Published in final edited form as:

N Engl J Med. 2010 July 1; 363(1): 11-23. doi:10.1056/NEJMoa0912321.

\title{
Stenting versus Endarterectomy for Treatment of Carotid-Artery Stenosis
}

\author{
Thomas G. Brott, M.D., Robert W. Hobson II, M.D. ${ }^{*}$, George Howard, Dr.P.H., Gary S. Roubin, \\ M.D., Ph.D., Wayne M. Clark, M.D., William Brooks, M.D., Ariane Mackey, M.D., Michael D. Hill, \\ M.D., Pierre P. Leimgruber, M.D., Alice J. Sheffet, Ph.D., Virginia J. Howard, Ph.D., Wesley S. \\ Moore, M.D., Jenifer H. Voeks, Ph.D., L. Nelson Hopkins, M.D., Donald E. Cutlip, M.D., David \\ J. Cohen, M.D., Jeffrey J. Popma, M.D., Robert D. Ferguson, M.D., Stanley N. Cohen, M.D.,
}

Copyright $\odot 2010$ Massachusetts Medical Society.

Address reprint requests to Dr. Brott at Mayo Clinic, Griffin 304, 4500 San Pablo Rd., Jacksonville, FL 32224, or at brott.thomas@mayo.edu.

*Deceased.

${ }^{\dagger}$ The Carotid Revascularization Endarterectomy vs. Stenting Trial (CREST) investigators and committee members are listed in the Appendix.

The content of this article is solely the responsibility of the authors and does not necessarily represent the official views of the NINDS or the NIH.

Dr. Roubin reports receiving consulting fees, honoraria, payments for the development of educational presentations, and travel reimbursement from Abbott Vascular, and royalties from Abbott Vascular and Cook; Dr. Mackey reports serving on the Board of Directors of the Canadian Stroke Consortium; Dr. Hill reports receiving consulting fees from Vernalis Group, honoraria from Hoffmann-La Roche Canada, Stem Cell Therapeutics, Portola Therapeutics, Sanofi-Aventis Canada, Bristol-Myers Squibb, and Merck Canada; grant support from Hoffmann- La Roche Canada, Bayer Canada, and Merck Canada; payment for the development of educational presentations from Boehringer-Ingelheim Canada; stock options from Calgary Scientific; and travel reimbursement from GE Canada Healthcare; Dr. Sheffet reports being a member of the Society for Clinical Trials; Dr. Hopkins reports serving on the boards of AccessClosure and Micrus; receiving consulting fees from Abbott Vascular, Boston Scientific, Cordis, Micrus, and W.L. Gore Endovascular; providing expert testimony for Brown and Tarantino; Bollinger, Ruberry and Garvey; Kevin Ricotta; Hamilton, Altman, Canale and Dillon; Martin, Clearwater and Bell; and Bunnell, Woulfe, Kirschbaum, Keller, McIntyre, Gregoire and Klein; receiving honoraria from Lenox Hill Hospital, Accumetrics, Society for Cardiac Angiography and Interventions (SCAI), Penn State College of Medicine, the Vascular Interventional Advances (VIVA) Conference, Northwestern University, Boston Scientific, the Advances in Cardiac and Endovascular Therapies (ACE) Conference, Cleveland Clinic, the International Symposium on Endovascular Therapy (ISET) Conference, Memorial Healthcare Systems, and Canisius College; payment for the development of educational presentations and speakers' fees from Abbott Vascular; stock options from Access-Closure, Boston Scientific, and Micrus; royalties from Informa UK, Cordis, Taylor and Francis Books, and Elsevier; grant support from Toshiba; and travel reimbursement from Leipzig Interventional Course (LINC), Micrus, AccessClosure, SCAI, Vascular Disease Conference, the Cardiovascular Research Foundation (CRF) Conference, All that Jazz, the EuroPCR Conference, Cedars-Sinai, the Multidisciplinary European Endovascular Therapy (MEET) Conference, the American Association of Neurological Surgeons (AANS), the VIVA Conference, the Congress of Neuro-surgeons Conference, the LINC Conference, the Transcatheter Cardiovascular Therapeutics (TCT) Conference, the Latin American Neurosurgery (CLAN) Conference, the Vascular and Endovascular Issues, Techniques, and Horizons (VEITH) Conference, the International Course on Carotid Angioplasty and Other Cerebrovascular Interventions (ICCA) Conference, the ISET Conference, the Innovation in Intervention: i2 Summit 2009 Research Foundation, NeuroVASX, W.L. Gore Endovascular, the Western Neurological Society, the Neurological Society of Australia Meeting, the Alta Bates Summer Stroke Conference, Toshiba, the Medicines Company Cleviprex Partnership Summit, the Cardiovascular Research Technologies Conference, the Neurosurgical Society of America Annual Meeting, Strategic Medical Seminars; and being an employee of University at Buffalo Neurosurgery; Dr. Cutlip reports receiving grant support from Cordis, travel reimbursement from Abbott Vascular, and additional funding for the Clinical Events Committee from Boston Scientific; Dr. David Cohen reports serving on the boards of Cordis and Medtronic and receiving consulting fees from Medtronic, grant support from Abbott Vascular, Boston Scientific, Eli Lilly-Daiichi Sankyo, and Bristol-Myers Squibb-Sanofi, payment for development of educational presentations from Eli Lilly, and travel reimbursement from Eli Lilly, Medtronic, and Cordis; Dr. Popma reports receiving consulting fees from Boston Scientific, Abbott Vascular, Cordis, Medtronic, Ablomed, AstraZeneca and Bristol-Myers Squibb; and grant support from Cordis, Medtronic, Boston Scientific, Abbott Vascular, and Abiomed; and Dr. Stanley Cohen reports receiving honoraria and payment for the development of educational presentations from the Boehringer-Ingelheim Speakers' Bureau. No other potential conflict of interest relevant to this article was reported.

Disclosure forms provided by the authors are available with the full text of this article at NEJM.org.

We thank the patients for their participation, their families, and the original principal investigator, Robert W. Hobson, II, M.D. (deceased), for his leadership and courage. 
Joseph L. Blackshear, M.D., Frank L. Silver, M.D., J.P. Mohr, M.D., Brajesh K. Lal, M.D., and James F. Meschia, M.D. for the CREST Investigators†

From Mayo Clinic, Jacksonville, FL (T.G.B., J.F.M., J.L.B.); University of Medicine and Dentistry of New Jersey, Newark (T.G.B., R.W.H., A.J.S.); University of Alabama at Birmingham, Birmingham

(G.H., V.J.H., J.H.V.); Lenox Hill Hospital (G.S.R.) and Columbia University Medical Center (J.P.M.) — both in New York; Oregon Health and Science University, Portland (W.M.C.); Central Baptist Hospital, Lexington, KY (W.B.); Centre Hospitalier Affilié Hôpital de l'Enfant-Jésus, Quebec City, QC (A.M.), University of Calgary, Calgary, AB (M.D.H.), and University of Toronto, Toronto (F.L.S.) - all in Canada; Spokane Cardiology Heart and Vascular Health, Spokane, WA (P.P.L.); UCLA, Los Angeles (W.S.M.); University at Buffalo, State University of New York, Buffalo (L.N.H.); Harvard Clinical Research Institute (D.E.C.) and Beth Israel Deaconess Medical Center, Harvard Medical School (J.J.P.) - both in Boston; Saint Luke's Mid America Heart Institute, Kansas City, MO (D.J.C.); MetroHealth Medical Center, Cleveland (R.D.F.); Nevada Neuroscience Institute, Las Vegas (S.N.C.); and University of Maryland Medical Center, Baltimore (B.K.L.).

\section{Abstract}

BACKGROUND—Carotid-artery stenting and carotid endarterectomy are both options for treating carotid-artery stenosis, an important cause of stroke.

METHODS-We randomly assigned patients with symptomatic or asymptomatic carotid stenosis to undergo carotid-artery stenting or carotid endarterectomy. The primary composite end point was stroke, myocardial infarction, or death from any cause during the periprocedural period or any ipsilateral stroke within 4 years after randomization.

RESULTS-For 2502 patients over a median follow-up period of 2.5 years, there was no significant difference in the estimated 4-year rates of the primary end point between the stenting group and the endarterectomy group $(7.2 \%$ and $6.8 \%$, respectively; hazard ratio with stenting, $1.11 ; 95 \%$ confidence interval, 0.81 to $1.51 ; \mathrm{P}=0.51)$. There was no differential treatment effect with regard to the primary end point according to symptomatic status $(\mathrm{P}=0.84)$ or $\operatorname{sex}(\mathrm{P}=0.34)$. The 4-year rate of stroke or death was $6.4 \%$ with stenting and $4.7 \%$ with endarterectomy (hazard ratio, $1.50 ; \mathrm{P}=0.03$ ); the rates among symptomatic patients were $8.0 \%$ and $6.4 \%$ (hazard ratio, $1.37 ; \mathrm{P}=0.14$ ), and the rates among asymptomatic patients were $4.5 \%$ and $2.7 \%$ (hazard ratio, $1.86 ; \mathrm{P}=0.07$ ), respectively.

Periprocedural rates of individual components of the end points differed between the stenting group and the endarterectomy group: for death $(0.7 \%$ vs. $0.3 \%, \mathrm{P}=0.18)$, for stroke $(4.1 \%$ vs. $2.3 \%, \mathrm{P}=$ $0.01)$, and for myocardial infarction $(1.1 \%$ vs. $2.3 \%, \mathrm{P}=0.03)$. After this period, the incidences of ipsilateral stroke with stenting and with endarterectomy were similarly low (2.0\% and $2.4 \%$, respectively; $\mathrm{P}=0.85$ ).

CONCLUSIONS-Among patients with symptomatic or asymptomatic carotid stenosis, the risk of the composite primary outcome of stroke, myocardial infarction, or death did not differ significantly in the group undergoing carotid-artery stenting and the group undergoing carotid endarterectomy. During the periprocedural period, there was a higher risk of stroke with stenting and a higher risk of myocardial infarction with endarterectomy. (ClinicalTrials.gov number, NCT00004732.)

Carotid-artery atherosclerosis is an important cause of ischemic stroke. ${ }^{1}$ Carotid endarterectomy has been established as effective treatment for both symptomatic patients and asymptomatic patients. $2^{-} 4$ Carotid-artery stenting is another option for treatment. The results of randomized trials comparing carotid-artery stenting and carotid endarterectomy for use in symptomatic patients are conflicting. $5^{-7}$ The primary aim of the Carotid Revascularization Endarterectomy vs. Stenting Trial (CREST) was to compare the outcomes of carotid-artery stenting with those of carotid endarterectomy among patients with symptomatic or asymptomatic extracranial carotid stenosis. 


\section{METHODS \\ STUDY DESIGN}

CREST is a randomized, controlled trial with blinded end-point adjudication. Ethics review boards at all participating centers approved the protocol. All patients provided written informed consent. The authors designed the study, gathered and analyzed the data, wrote the manuscript, made the decision to publish the findings, vouch for the completeness and accuracy of the data, and attest to the fidelity of the report to the study protocol. Abbott Vascular Solutions (formerly Guidant) donated the Accunet and Acculink systems to all CREST centers in Canada and to CREST centers in the United States that were at Veterans Affairs sites. Abbott has a nonvoting seat on the CREST Executive Committee and reviewed the final draft of the manuscript before submission. Abbott assisted with CREST site monitoring and was responsible for all site monitoring of the Canadian centers. The full protocol and statistical analysis plan can be found in the Supplementary Appendix with the full text of this article at NEJM.org.

\section{CENTERS AND INVESTIGATIONS}

We enrolled patients at 108 centers in the United States and 9 in Canada. Centers were required to have a team consisting of a neurologist, an interventionist, a surgeon, and a research coordinator. Patients could not be randomly assigned to a treatment group until the operators performing carotid-artery stenting and carotid endarterectomy had been certified. Certification was achieved by 477 surgeons, whose clinical results were audited by means of a validated selection process ${ }^{8}$ documenting that they performed more than 12 procedures per year and that the rates of complications and death were less than $3 \%$ among asymptomatic patients and less than 5\% among symptomatic patients. The 224 interventionists were certified after satisfactory evaluation of their endovascular experience, carotid-stenting results, participation in hands-on training, and participation in a lead-in phase of training (see additional details in the Supplementary Appendix). ${ }^{9}$

\section{SELECTION OF STUDY PATIENTS}

Patients were considered to be symptomatic if they had had a transient ischemic attack, amaurosis fugax, or minor nondisabling stroke involving the study carotid artery within 180 days before randomization. Eligibility criteria were stenosis of $50 \%$ or more on angiography, $70 \%$ or more on ultrasonography, or $70 \%$ or more on computed tomographic angiography or magnetic resonance angiography if the stenosis on ultrasonography was 50 to $69 \%$. Eligibility was extended in 2005 to include asymptomatic patients, for whom the criteria were stenosis of $60 \%$ or more on angiography, $70 \%$ or more on ultrasonography, or $80 \%$ or more on computed tomographic angiography or magnetic resonance angiography if the stenosis on ultrasonography was 50 to $69 \%$. Patients were excluded if they had had a previous stroke that was sufficiently severe to confound the assessment of end points or if they had chronic atrial fibrillation, paroxysmal atrial fibrillation that had occurred within the preceding 6 months or that necessitated anticoagulation therapy, myocardial infarction within the previous 30 days, or unstable angina. Additional eligibility criteria were clinical and anatomical suitability, before randomization, for management by means of either of the study revascularization techniques. The full eligibility criteria have been published elsewhere. ${ }^{10}$

\section{RANDOMIZATION}

Eligible patients were randomly assigned, with the use of a Web-based system, to undergo either carotid-artery stenting or carotid endarterectomy. Randomization was based on a permuted-block design (with random block sizes of 2, 4, or 6), was stratified according to center and symptomatic status, and was performed after the patient, surgeon, and interventionist could arrange for a date for the procedure within 2 weeks. 


\section{STENTING AND ENDARTERECTOMY}

Carotid-artery stenting and carotid endarterectomy were performed according to published guidelines. ${ }^{9}, 11,12$ For carotid-artery stenting, the protocol specified use of the RX Acculink stent and, whenever feasible, the RX Accunet embolic-protection device. At least 48 hours before carotid-artery stenting, patients received aspirin, at a dose of $325 \mathrm{mg}$ twice daily, and clopidogrel at a dose of $75 \mathrm{mg}$ twice daily. When carotid-artery stenting was scheduled for within 48 hours after randomization, $650 \mathrm{mg}$ of aspirin and $450 \mathrm{mg}$ of clopidogrel were given 4 or more hours before the procedure. After the procedure, patients received one or two 325$\mathrm{mg}$ doses of aspirin daily for 30 days and either clopidogrel, $75 \mathrm{mg}$ daily, or ticlopidine, 250 $\mathrm{mg}$ twice daily, for 4 weeks. The continuation of antiplatelet therapy for more than 4 weeks after the procedure was recommended for all patients who had undergone carotid-artery stenting. At least 48 hours before carotid endarterectomy, patients received $325 \mathrm{mg}$ of aspirin daily and continued to receive that dose for a year or more. Alternatives to this regimen were ticlopidine given at a dose of $250 \mathrm{mg}$ twice daily, clopidogrel at a dose of $75 \mathrm{mg}$ daily, aspirin at a dose of $81 \mathrm{mg}$ daily, or aspirin and extended-release dipyridamole twice daily (Table 1 in the Supplementary Appendix). Patients undergoing either study procedure received medical therapy that was consistent with the current standard of care, including treatment of hypertension and hyperlipidemia.

\section{FOLLOW-UP ASSESSMENTS OF END POINTS}

Neurologic evaluation was performed at baseline and 18 to 54 hours after the study procedure, 1 month afterward, and every 6 months thereafter. The evaluation consisted of the use of the National Institutes of Health (NIH) Stroke Scale (NIHSS), 13 the modified Rankin scale, and the Transient Ischemic Attack (TIA)-Stroke Questionnaire.14 The NIHSS is a 15-item neurologic-impairment scale, with possible scores ranging from 0 (no deficit) to 42 (quadriplegia and coma). The modified Rankin scale is a disability scale on which scores can range from 0 (no symptoms) to 6 (death). The TIA-Stroke Questionnaire consists of a question about whether there is a history of TIA, one about whether there is a history of stroke, and six questions about whether there was a sudden onset of any of various focal neurologic symptoms consistent with TIA or stroke.

Cardiac-enzyme levels were measured before the study procedure and 6 to 8 hours after the procedure. Electrocardiography (ECG) was performed before stenting or endarterectomy, as well as 6 to 48 hours and 1 month afterward. Carotid ultrasonography was performed before the study procedure; 1,6 , and 12 months afterward; and annually thereafter.10 A follow-up telephone interview, including administration of the TIA-Stroke Questionnaire, 14 was conducted at 3 months and every 6 months thereafter. General health status was assessed at baseline, at 2 weeks, 1 month after the procedure, and 1 year after randomization, with the use of the Medical Outcomes Study 36-Item Short-Form Health Survey (SF-36), which evaluates eight dimensions of health, with scores for each ranging from 0 to 100, and higher scores indicating better health status. The SF-36 provides summary scales for overall physical and mental health, with norm-based standardization of the scores to a mean of 50 and a standard deviation of $10.15,16$

The primary end point was the composite of any stroke, myocardial infarction, or death during the periprocedural period or ipsilateral stroke within 4 years after randomization. When the procedure was performed within 30 days after randomization, the periprocedural period was defined as the period from randomization through 30 days after the procedure. When the procedure was not performed within 30 days after randomization, the periprocedural period was defined as the period from randomization through 36 days after randomization. Study committees unaware of the treatment assignments adjudicated stroke and myocardial infarction. 
Stroke was defined as an acute neurologic event with focal symptoms and signs, lasting for 24 hours or more, that were consistent with focal cerebral ischemia. The adjudication process was initiated after a clinically significant neurologic event, any positive response on the TIA-Stroke Questionnaire, or an increase by 2 points or more in the NIHSS score. Stroke was defined as major stroke on the basis of clinical data or if the NIHSS score was 9 or higher 90 days after the procedure. Myocardial infarction was defined by a creatine kinase MB or troponin level that was twice the upper limit of the normal range or higher according to the center's laboratory, in addition to either chest pain or symptoms consistent with ischemia or ECG evidence of ischemia, including new ST-segment depression or elevation of more than $1 \mathrm{~mm}$ in two or more contiguous leads according to the core laboratory. ${ }^{17}$

\section{STATISTICAL ANALYSES}

Analyses were aimed at testing for superiority. The null hypothesis was that the two study treatments are equivalent; the alternative hypothesis was that the treatments differ. A sample size of 2500 patients was selected to provide a statistical power of $90 \%$ to detect a hazard ratio for the primary end point of less than 0.54 or more than 1.49 with stenting as compared with endarterectomy, approximating an absolute difference of 1.2 percentage points per year in the rate of the primary end point between the two treatment groups. Intention-to-treat survival analysis was used, and Kaplan-Meier survival curves were plotted. Two interim analyses were performed with the use of O'Brien-Fleming boundaries, ${ }^{18}$ the first after approximately one fifth of the patients had been recruited, and the second after approximately half the patients had been recruited. Multiple-imputation techniques ${ }^{19}$ were used to assess bias from differential rates of withdrawal from the study in the two groups.

Secondary aims included estimating the modification of the treatment effect by symptomatic status, sex, and age, which were assessed through inclusion of the interaction terms in the proportional-hazards models (as a single indicator variable for sex and symptomatic status and a linear term for age). The analyses of age were planned before data analysis began but were not described in the study protocol. Longitudinal random-effect growth-curve models ${ }^{20}$ were used to evaluate the effect of periprocedural events on health status at 1 year, as assessed with the use of the SF-36 physical and mental health scales. These models were adjusted for symptomatic status, sex, age, and baseline health status.

\section{RESULTS}

\section{STUDY POPULATION AND TREATMENTS}

From December 2000 through July 2008, a total of 2522 patients were randomly assigned to one of the two treatments (Fig. 1). After randomization, among the 1271 patients randomly assigned to undergo carotid-artery stenting, $36(2.8 \%)$ withdrew consent, $73(5.7 \%)$ underwent carotid endarterectomy, and $33(2.6 \%)$ were lost to follow-up; among the 1251 patients assigned to carotid endarterectomy, 64 (5.1\%) withdrew consent, 13 (1.0\%) underwent carotidartery stenting, and 47 (3.8\%) were lost to follow-up.

Quality-control and site-monitoring activities resulted in the detection of irregular data from one center. The principal investigator and the Office of Research Integrity of the Department of Health and Human Services were notified and subsequently determined that some data were fabricated. All data from this center (which had enrolled 9 patients undergoing carotid-artery stenting and 11 undergoing carotid endarterectomy) were excluded before any analyses were performed, resulting in a cohort of 2502 patients for all analyses.

Dyslipidemia was more common among patients in the endarterectomy group than among those in the stenting group $(85.8 \%$ vs. $82.9 \%, \mathrm{P}=0.048)$, both groups had high rates of vascular 
risk factors, and more than $80 \%$ of patients had severe stenosis (Table 1). Baseline characteristics are reported according to symptomatic status in Tables 2 and 3 in the Supplementary Appendix.

The median time from randomization to the procedure was 6 days for carotid-artery stenting and 7 days for carotid endarterectomy. Stenting was performed with embolic protection in $96.1 \%$ of patients assigned to the stenting group, and endarterectomy was performed with the use of general anesthesia in $90.0 \%$ of patients assigned to the endarterectomy group. The median duration of follow-up was 2.5 years. During that time, the level or prevalence of selected risk factors remained similar between the two treatment groups, except for current smoking, the prevalence of which was similar at baseline (26.4\% with stenting and $26.1 \%$ with endarterectomy) but for which differences developed during follow-up (21.8\% with stenting vs. $13.8 \%$ with endarterectomy, $\mathrm{P}=0.03$ ) (Table 4 in the Supplementary Appendix).

\section{PRIMARY END POINT}

There was no significant difference in the estimated 4-year rates of the primary end point between carotid-artery stenting and carotid endarterectomy $(7.2 \%$ and $6.8 \%$, respectively; hazard ratio for stenting, $1.11 ; 95 \%$ confidence interval $[\mathrm{CI}], 0.81$ to $1.51 ; \mathrm{P}=0.51$ ) (Table 2 and Fig. 2A). Findings from the multiple-imputation analysis suggested that the withdrawal of patients in each group did not introduce bias. Of the end-point events, 13 strokes were fatal ( 7 in the stenting group and 6 in the endarterectomy group), and 1 myocardial infarction was fatal (in the endarterectomy group). During the periprocedural period, the incidence of the primary end point was similar with carotid-artery stenting and carotid endarterectomy (5.2 and $4.5 \%$, respectively; hazard ratio for stenting, $1.18 ; 95 \% \mathrm{CI}, 0.82$ to $1.68 ; \mathrm{P}=0.38$ ), although the rates of the individual end points differed between the stenting group and the endarterectomy group (death, $0.7 \%$ vs. $0.3 \% ; \mathrm{P}=0.18$; stroke, $4.1 \%$ vs. $2.3 \% ; \mathrm{P}=0.01$; myocardial infarction, $1.1 \%$ vs. $2.3 \%$; $\mathrm{P}=0.03$ ) (Table 2, and Fig. 1 in the Supplementary Appendix). After the periprocedural period, the incidence of ipsilateral stroke was similarly low with carotid-artery stenting and with carotid endarterectomy $(2.0 \%$ and $2.4 \%$, respectively; $\mathrm{P}=0.85)$.

Prespecified analyses did not show a modification of the treatment effect by symptomatic status $(\mathrm{P}=0.84)$ or by sex $(\mathrm{P}=0.34)$ (Table 5 in the Supplementary Appendix). However, an interaction between age and treatment efficacy was detected $(\mathrm{P}=0.02)$ (Fig. 2B and 2C), with a crossover at an age of approximately 70 years; carotid-artery stenting tended to show greater efficacy at younger ages, and carotid endarterectomy at older ages.

\section{PRESPECIFIED SECONDARY ANALYSES}

During the periprocedural period, rates of the primary end point did not differ significantly between the stenting group and the endarterectomy group among symptomatic patients $(6.7 \%$ vs. $5.4 \%$; hazard ratio for stenting, $1.26 ; 95 \% \mathrm{CI}, 0.81$ to 1.96 ) or among asymptomatic patients ( $3.5 \%$ vs. $3.6 \%$; hazard ratio, $1.02 ; 95 \%$ CI, 0.55 to 1.86 ) (Table 3). Cranial-nerve palsies were less frequent during the periprocedural period with carotid-artery stenting $(0.3 \%$, vs. $4.7 \%$ with carotid endarterectomy; hazard ratio, $0.07 ; 95 \% \mathrm{CI}, 0.02$ to 0.18 ). Additional serious adverse events are detailed in Table 6 in the Supplementary Appendix. The 4-year rate of stroke or death was $6.4 \%$ in the stenting group as compared with $4.7 \%$ in the endarterectomy group (hazard ratio, $1.50 ; 95 \% \mathrm{CI}, 1.05$ to $2.15 ; \mathrm{P}=0.03$ ); the respective rates were $8.0 \%$ and $6.4 \%$ among symptomatic patients (hazard ratio, $1.37 ; 95 \% \mathrm{CI}, 0.90$ to $2.09 ; \mathrm{P}=0.14$ ) and $4.5 \%$ and $2.7 \%$ among asymptomatic patients (hazard ratio, $1.86 ; 95 \% \mathrm{CI}, 0.95$ to $3.66 ; \mathrm{P}=0.07$ ).

\section{POST HOC ANALYES}

Longitudinal growth-curve models were used to estimate the effect of periprocedural stroke and myocardial infarction on health status at 1 year (Fig. 2 and 3 in the Supplementary 
Appendix). Major stroke and minor stroke were found to have an effect on physical health at 1 year, according to the SF-36 physical component scale (mean effect estimates, -15.8 points [95\% CI, -25.1 to -6.4 ] and -4.5 points [ $95 \% \mathrm{CI},-7.9$ to -1.2 ], respectively), whereas the effect of periprocedural myocardial infarction was less certain (mean effect estimate, -3.0 points [ $95 \% \mathrm{CI},-7.1$ to 1.1$]$ ). Minor stroke had a significant effect on mental health at 1 year, as measured on the SF-36 mental component scale (mean effect estimate, -3.4 points [95\% CI, -6.3 to -0.5$]$ ). The likelihood of the primary end point was not significantly affected by the medical specialty of the interventionist performing the carotid-artery stenting $(\mathrm{P}=0.51)$ (Table 7 in the Supplementary Appendix). ${ }^{9}$

\section{DISCUSSION}

Our CREST results indicate that carotid-artery stenting and carotid endarterectomy were associated with similar rates of the primary composite outcome - periprocedural stroke, myocardial infarction, or death and subsequent ipsilateral stroke - among men and women with either symptomatic or asymptomatic carotid stenosis. However, the incidence of periprocedural stroke was lower in the endarterectomy group than in the stenting group, whereas the incidence of periprocedural myocardial infarction was lower in the stenting group. These countervailing effects during the periprocedural period resulted in similar rates of the primary outcomes because the rates of events after the periprocedural period were similar in the two groups. Although previous studies have indicated that both stroke and myocardial infarction are associated with substantial morbidity and mortality, ${ }^{21,22}$ quality-of-life analyses among survivors at 1 year in our trial indicate that stroke had a greater adverse effect on a broad range of health-status domains than did myocardial infarction.

The selection of patients for either carotid-artery stenting or carotid endarterectomy may require attention to age, with younger patients having a slightly better outcome with carotidartery stenting and older patients having a better outcome with carotid endarterectomy. 23 The association between older age and increased risk of adverse events after carotid-artery stenting was seen in our lead-in cohort, 9 the Stent-Protected Angioplasty versus Carotid Endarterectomy (SPACE) trial (Current Controlled Trials number, ISRCTN57874028), ${ }^{6}$ and the International Carotid Stenting Study (ICSS; ISRCTN25337470).24 An effect of age on differences between carotid-artery stenting and carotid endarterectomy was found in the SPACE trial25 as well as in our study. Mechanisms underlying the increased risk with carotidartery stenting in very elderly patients probably include vascular tortuosity and severe vascular calcification. 23

The periprocedural outcomes for carotid-artery stenting and carotid endarterectomy reported here are the best reported from a randomized, carotid-revascularization study that incorporated pre- and postprocedural medical, neurologic, ECG, and biomarker evaluations (Table 3). The rate of stroke or death among our symptomatic patients after carotid-artery stenting $(6.0 \%)$ was lower than the corresponding rates in the SPACE trial (6.8\%, not including nonipsilateral stroke), the Endarterectomy versus Angioplasty in Patients with Symptomatic Severe Carotid Stenosis (EVA-3S) trial (ClinicalTrials.gov number, NCT00190398) (9.6\%), and ICSS (7.4\%). The rate of stroke or death among our symptomatic patients after carotid endarterectomy (3.2\%) was also lower than the corresponding percentage in SPACE (6.3\%) and was similar to the corresponding percentage in EVA-3S (3.9\%) as well as that in ICSS (3.4\%); in ICSS, the protocol did not require formal examination until 30 days after the procedure. Among asymptomatic patients, the rate of stroke or death in the carotid-artery stenting group in our trial (2.5\%) was similar to that in the Asymptomatic Carotid Atherosclerosis Study (ACAS) ( $2.3 \%$, excluding patients older than 79 years) 8 and was lower than that in the Asymptomatic Carotid Surgery Trial (ACST; ISRCTN26156392) (3.1\%),26 and the rate of stroke and death in our carotid-endarterectomy group (1.4\%) was lower than that in ACAS and ACST. 
The improved periprocedural outcomes in CREST as compared with previous trials may reflect the effective surgeon credentialing, assimilation of evolving endovascular technology, and rigorous training and credentialing of carotid-artery stenting operators. ${ }^{9}$ The differential results for myocardial infarction and stroke offer opportunities for improvement. To reduce the risk of stroke after carotid-artery stenting, improvements in training and technique, embolic protection and stent design, and patient selection (especially among patients older than 70 years of age) hold promise. ${ }^{23,27}$ To reduce the risk of myocardial infarction after carotid endarterectomy, more detailed preoperative cardiovascular evaluation and the use of dual antiplatelet therapy, statins, 28 cardioprotective pharmacotherapy,29 or local anesthesia could be investigated.

The clinical durability of carotid-artery stenting and carotid endarterectomy is important. The rates of ipsilateral stroke during our follow-up period $-2.0 \%$ with carotid-artery stenting and $2.4 \%$ with carotid endarterectomy — are similar to the rates in the SPACE trial and EVA-3S, suggesting excellent durability for up to 4 years. Because the life expectancy of our averageaged patient is 15 years after the procedure, ${ }^{30}$ outcomes are being assessed in CREST out to 10 years.

The CREST study does have limitations. The certification requirements were important for patient safety, but they limit the generalizability of the results and conclusions to similarly qualified operators. One interventional carotid-artery stenting system was used. Improvements were incorporated into that system as technology evolved. Although the use of one system facilitated standardization, external validity may have been affected by our prohibition on the use of other stent systems. The addition of asymptomatic patients and the anticipated lower event rate for that group had the potential to compromise the statistical power. However, that lower event rate was offset by the higher number of events associated with the extended enrollment and follow-up periods. The use of medical therapy alone was not studied, sharply limiting our ability to generalize the results. For example, the rates of ipsilateral and contralateral stroke were similar in the two groups after the periprocedural period. For asymptomatic patients, this similarity could indicate that revascularization is durable or that asymptomatic carotid stenosis is benign if treated medically.

In conclusion, carotid revascularization performed by highly qualified surgeons and interventionists is effective and safe. Stroke was more likely after carotid-artery stenting. Myocardial infarction was more likely after carotid endarterectomy, but the effect on the quality of life was less than the effect of stroke. Younger patients had slightly fewer events after carotidartery stenting than after carotid endarterectomy; older patients had fewer events after carotid endarterectomy. The low absolute risk of recurrent stroke suggests that both carotid-artery stenting and carotid endarterectomy are clinically durable and may also reflect advances in medical therapy.

\section{Supplementary Material}

Refer to Web version on PubMed Central for supplementary material.

\section{Acknowledgments}

Supported by the National Institute of Neurological Disorders and Stroke (NINDS) and the NIH (R01 NS 038384) and supplemental funding from Abbott Vascular Solutions (formerly Guidant), including donations of Accunet and Acculink systems, equivalent to approximately $15 \%$ of the total study cost, to CREST centers in Canada and to CREST centers in the United States that were at Veterans Affairs sites. 


\section{APPENDIX}

The CREST investigators and committee members were as follows - Principal investigators (in order of decreasing number of patients who were randomly assigned to a treatment group): W. Clark, Oregon Health and Science University, Portland; W. Brooks, Central Baptist Hospital, Lexington, KY; A. Mackey, Centre Hospitalier Affilié Universitaire de QuébecHôpital de l'Enfant-Jésus, Quebec City, QC, Canada; M. Hill, A. Buchan, University of Calgary-Foothills Medical Centre, Calgary, AB, Canada; P. Leimgruber, Deaconess Medical Center-Northwest Cardiovascular Research Institute, Spokane, WA; V. Mantese, St. John's Mercy Medical Center, St. Louis; C. Timaran, University of Texas Southwestern Medical School, Dallas; L.N. Hopkins, State University of New York, Buffalo; D. Chiu, Methodist Hospital, Houston; R. Begg, Tri-State Medical Group, Beaver, PA; Z. Jamil, St. Michael's Medical Center, Newark, NJ; R. Hye, Kaiser Permanente San Diego Medical Center, San Diego, CA; B. Demaerschalk, Mayo Clinic, Scottsdale, AZ; O.W. Brown, Beaumont Hospital, Royal Oak, MI; G.S. Roubin, S. Iyer, Lenox Hill Hospital, New York; D. Heck, Forsyth Medical Center, Winston-Salem, NC; R. Farb, W. Montanera, S.K. Lee, Toronto Western Hospital, Toronto; I. Altafullah, North Memorial Medical Center, Golden Valley, MN; G. Ansel, MidWest Cardiology Research Foundation, Columbus, OH; A. Sam II, Vascular Specialty Associates, Baton Rouge, LA; N. Gonzales, M. Campbell, J. Choi, University of Texas Medical School, Houston; P. Soukas, St. Elizabeth's Medical Center, Boston; L. Wechsler, University of Pittsburgh Medical Center-Shadyside Hospital and Presbyterian Hospital, Pittsburgh; D. Clair, K. Ouriel, Cleveland Clinic, Cleveland; M. Reisman, W. Gray, Swedish Medical Center, Seattle; J. Eidt, University of Arkansas for Medical Sciences-Central Arkansas Veterans Healthcare System, Little Rock; S. Orlow, Northern Indiana Research Alliance, Fort Wayne; J. Burke, S. Sorenson, P.J. Casterella, Intermountain Medical Center, Salt Lake City; M. Malas, K. Murphy, Johns Hopkins Medical Institutions, Baltimore; M. Rinaldi, Sanger Heart and Vascular Institute, Charlotte, NC; K. Rosenfield, Massachusetts General Hospital, Boston; C. Sternbergh III, R. Felberg, Ochsner Health System, New Orleans; R. McCann, T. Smith, Duke University Medical Center, Durham, NC; C. O'Mara, Mississippi Baptist Medical Center, Jackson; A. Hakaim, Mayo Clinic, Jacksonville, FL; B. Katzen, Baptist Cardiac and Vascular Institute, Miami; R. Spetzler, Barrow Neurological Institute, Phoenix, AZ; A. Pucillo, Westchester Medical Center, Valhalla, NY; J. Elmore, Geisinger Medical Center, Danville, PA; W. Jordan, University of Alabama at Birmingham, Birmingham; D. Lew, Leesburg Regional Medical Center, Leesburg, FL; R. Powell, Dartmouth Hitchcock Medical Center, Lebanon, NH; R. Bulas, the Christ Hospital, Cincinnati; B. Kluck, Lehigh Valley Hospital, Allentown, PA; J. Rapp, San Francisco Veterans Affairs Medical Center, San Francisco; G. Mishkel, Prairie Education and Research Cooperative, Springfield, IL; F. Weaver, University of Southern California, Los Angeles; M. Nazzal, University of Toledo Medical Center, Toledo, OH; C. Narins, University of Rochester Medical Center, Rochester, NY; R. Molnar, Michigan Vascular Research Center, Flint; M. Eskandari, Northwestern Memorial Hospital, Chicago; H. Aronow, Michigan Heart and Vascular Institute, Ann Arbor; F. Shawl, Washington Adventist Hospital, Takoma Park, MD; R. Rosenwasser, Thomas Jefferson University, Philadelphia; H. Chastain, Parkview Research Center, Fort Wayne, IN; M. Foster, Baptist Hospital West, Knoxville, TN; R. Raabe, Providence Medical Research Center, Spokane, WA; D. Pelz, London Health Sciences Centre, London, ON, Canada; G. Stotts, Ottawa Hospital, Ottawa; H. Cloft, Mayo Clinic, Rochester, MN; L. Heller, W. Knopf, St. Joseph's Hospital of Atlanta, Atlanta; B. Reddy, Piedmont Hospital-Fuqua Heart Center, Atlanta; K. Hodgson, Southern Illinois School of Medicine, Springfield; K. Fraser, Order of

St. Francis Saint Francis Medical Center, Peoria, IL; W. Gray, J.P. Mohr, Columbia University Medical Center-New York Presbyterian Hospital, New York; A. Shepard, D. Reddy, Henry Ford Hospital, Detroit; W. Montanera, St. Michael's Hospital, Toronto; W. Moore, UCLA, Los Angeles; E. Chaikof, B. Stern, Emory University Hospital-Atlanta Veterans Affairs Medical Center, Atlanta; S. Johnson, Cardiovascular Research Foundation-Cardiovascular 
Associates, Elk Grove, IL; R. Zelman, Cape Cod Research Institute, Hyannis, MA; A. Evans, University of Virginia Health System, Charlottesville; D. Burkart, St. Joseph Medical Center, Kansas City, MO; D. Bandyk, University of South Florida, Tampa; P. Karanjia, Marshfield Clinic, Marshfield, WI; J. Zarghami, Providence Hospital and Medical Centers, Southfield, MI; A. Arthur, J. Barr, Baptist Memorial Hospital, Memphis, TN; M. Mehta, Vascular Interventional Project, Albany, NY; A. Comerota, Jobst Vascular Center, Toledo, OH; K. Natarajan, K. Krol, St. Vincent Hospital, Indianapolis; J. Howington, St. Joseph/Candler Health System, Savannah, GA; D. Selchen, Trillium Health Centre, Mississauga, ON, Canada; M. Schermerhorn, F.W. LoGerfo, Beth Israel Deaconess Medical Center, Boston; S. Laster, St. Luke's Hospital, Kansas City, MO; M. Sanz, St. Patrick Hospital, Missoula, MT; E. Lopez del Valle, Morton Plant Hospital, Clearwater, FL; J. Andriole, Orlando Regional Healthcare, Orlando, FL; A. Ringer, University of Cincinnati, Cincinnati; J. Martin, Anne Arundel Medical Center, Annapolis, MD; R. Guzman, University of Manitoba, Winnipeg, MB, Canada; P. Teal, Vancouver General Hospital, Vancouver, BC, Canada; F. Hellinger, Florida Hospital, Orlando; G. Petrossian, R.B. Berroya, St. Francis Hospital, Roslyn, NY; M. Bates, Charleston Area Medical Center, Charleston, WV; J. Mills, University of Arizona College of Medicine, Tucson; M. Golden, R. Fairman, Hospital of the University of Pennsylvania, Philadelphia; A. Mansour, Butterworth Hospital, Grand Rapids, MI; A. MacBeth, H. Madyoon, St. Joseph's Medical Center, Stockton, CA; L.A. Iannone, Iowa Heart Center, Des Moines; K. Hansen, Wake Forest University Health Sciences, Winston-Salem, NC; J. Biller, Loyola University Medical Center, Maywood, IL; J. Shuck, Christiana Care Health Services, Newark, DE; P. Gobin, Weill Cornell Medical College of New York Presbyterian Hospital, New York; K. Dauterman, Rogue Valley Medical Center, Medford, OR; J. Melton, Oklahoma Foundation for Cardiovascular Research, Oklahoma City; D. Benckart, Allegheny General Hospital, Pittsburgh; W. Lesley, Scott and White Memorial Hospital, Temple, TX; M. Belkin, Brigham and Women's Hospital, Boston; T. Bajwa, St. Luke's Medical Center, Milwaukee; S. Myla, Hoag Memorial Hospital, Newport Beach, CA; J. Snell, Rush University Medical Center, Chicago; H. Shownkeen, Central DuPage Hospital, Winfield, IL; A. Abou-Chebl, University of Louisville, Louisville, KY; Executive Committee: T.G. Brott (chair), R.W. Hobson, II (deceased), K.W. Beach, D.J. Cohen, J. Cordell, D.E. Cutlip, R.D. Ferguson, L.N. Hopkins, G. Howard, V.J. Howard, L. Keene, B.K. Lal, J.F. Meschia, J.P. Mohr, W.S. Moore, J. Popma, G.S. Roubin, A.J. Sheffet, F.L. Silver; Stroke Adjudication Committee: S.N. Cohen (chair), J. Biller, J.P. Broderick, S. Chaturvedi, M.A. Kalafut, E.J. Skalabrin; Myocardial Infarction Adjudication Committee: J.L. Blackshear (chair), S.P. Glasser, R.J. Prineas; Data and Safety Monitoring Board: J. Marsh (chair), R. Higashida, G. Lamas, B. Tilley, M. Walker, and G.R. Cutter (20012002).

\section{REFERENCES}

1. Petty GW, Brown RD Jr, Whisnant JP, Sicks JD, O'Fallon WM, Wiebers DO. Ischemic stroke subtypes: a population-based study of incidence and risk factors. Stroke 1999;30:2513-2516. [PubMed: 10582970]

2. Goldstein LB, Adams R, Alberts MJ, et al. Primary prevention of ischemic stroke: a guideline from the American Heart Association/American Stroke Association Stroke Council: cosponsored by the Atherosclerotic Peripheral Vascular Disease Interdisciplinary Working Group; Cardiovascular Nursing Council; Clinical Cardiology Council; Nutrition, Physical Activity, and Metabolism Council; and the Quality of Care and Outcomes Research Interdisciplinary Working Group: The American Academy of Neurology affirms the value of this guideline. Stroke 2006;37:1583-1633. [Erratum, Stroke 2007;38:207.]. [PubMed: 16675728]

3. Adams RJ, Albers G, Alberts MJ, et al. Update to the AHA/ASA recommendations for the prevention of stroke in patients with stroke and transient ischemic attack. Stroke 2008;39:1647-1652. [PubMed: 18322260] 
4. Ederle J, Featherstone RL, Brown MM. Percutaneous transluminal angioplasty and stenting for carotid artery stenosis. Cochrane Database Syst Rev 2007;4:CD000515. [PubMed: 17943745]

5. Yadav JS, Wholey MH, Kuntz RE, et al. Protected carotid-artery stenting versus endarterectomy in high-risk patients. N Engl J Med 2004;351:1493-1501. [PubMed: 15470212]

6. Ringleb PA, Allenberg J, Bruckmann H, et al. 30 Day results from the SPACE trial of stent-protected angioplasty versus carotid endarterectomy in symptomatic patients: a randomised non-inferiority trial. Lancet 2006;368:1239-1247. [Erratum, Lancet 2006;368:1238.]. [PubMed: 17027729]

7. Mas JL, Chatellier G, Beyssen B, et al. Endarterectomy versus stenting in patients with symptomatic severe carotid stenosis. N Engl J Med 2006;355:1660-1671. [PubMed: 17050890]

8. Executive Committee for the Asymptomatic Carotid Atherosclerosis Study. Endarterectomy for asymptomatic carotid artery stenosis. JAMA 1995;273:1421-1428. [PubMed: 7723155]

9. Hopkins LN, Rougin GS, Chakhtoura EY, et al. The Carotid Revascularization Endarterectomy versus Stenting Trial: credentialing of interventionalists and final results of lead-in phase. J Stroke Cerebrovasc Dis 2010;19:153-162. [PubMed: 20189092]

10. Sheffet AJ, Roubin G, Howard G, et al. Design of the Carotid Revascularization Endarterectomy vs. Stenting Trial (CREST). Int J Stroke 2010;5:40-46. [PubMed: 20088993]

11. Hobson RW II. CREST (Carotid Revascularization Endarterectomy versus Stent Trial): background, design, and current status. Semin Vasc Surg 2000;13:139-143. [PubMed: 10879554]

12. Moore WS, Vescera CL, Robertson JT, Baker WH, Howard VJ, Toole JF. Selection process for surgeons in the Asymptomatic Carotid Atherosclerosis Study. Stroke 1991;22:1353-1357. [PubMed: 1750041]

13. Brott T, Adams HP Jr, Olinger CP, et al. Measurements of acute cerebral infarction: a clinical examination scale. Stroke 1989;20:864-870. [PubMed: 2749846]

14. Meschia JF, Brott TG, Chukwudelunzu FE, et al. Verifying the stroke-free phenotype by structured telephone interview. Stroke 2000;31:1076-1080. [PubMed: 10797168]

15. Ware JE Jr, Sherbourne CD. The MOS 36-Item Short-Form Health Survey (SF-36). I. Conceptual framework and item selection. Med Care 1992;30:473-483. [PubMed: 1593914]

16. Ware JE Jr, Kosinski M, Bayliss MS, McHomey CA, Rogers WH, Raczek A. Comparison of methods for the scoring and statistical analysis of SF-36 health profile and summary measures: summary of results from the Medical Outcomes Study. Med Care 1995;33 Suppl:AS264-AS279. [PubMed: 7723455]

17. Rautaharju PM, MacInnis PJ, Warren JW, Wolf HK, Rykers PM, Calhoun HP. Methodology of ECG interpretation in the Dalhousie Program: NOVACODE ECG classification procedures for clinical trials and population health surveys. Methods Inf Med 1990;29:362-374. [PubMed: 2233384]

18. O'Brien PC, Fleming TR. A multiple testing procedure for clinical trials. Biometrics 1979;35:549556. [PubMed: 497341]

19. Taylor JMG, Cooper KL, Wei JT, Sarma AV, Raghunathan TE, Heeringa SG. Use of multiple imputation to correct for nonresponse bias in a survey of urologic symptoms among AfricanAmerican men. Am J Epidemiol 2002;156:774-782. [PubMed: 12370166]

20. Jennrich RI, Schluchter MD. Unbalanced repeated-measures models with structured covariance matrices. Biometrics 1986;42:805-820. [PubMed: 3814725]

21. van Wijk I, Koudstaal P, Kappelle LJ, et al. Long-term occurrence of death and cardiovascular events in patients with transient ischaemic attack or minor ischaemic stroke: comparison between arterial and cardiac source of the index event. J Neurol Neurosurg Psychiatry 2008;79:895-899. [PubMed: 18096680]

22. Landesberg G, Shatz V, Akopnik I, et al. Association of cardiac troponin, CK-MB, and postoperative myocardial ischemia with long-term survival after major vascular surgery. J Am Coll Cardiol 2003;42:1547-1554. [PubMed: 14607436]

23. Chiam PT, Roubin GS, Iyer SS, et al. Carotid artery stenting in elderly patients: importance of case selection. Catheter Cardiovasc Interv 2008;72:318-324. [PubMed: 18726954]

24. Ederle J, Dobson J, Featherstone RL, et al. Carotid artery stenting compared with endarterectomy in patients with symptomatic carotid stenosis (International Carotid Stenting Study): an interim analysis of a randomised controlled trial. Lancet 2010;375:985-997. [PubMed: 20189239] 
25. Stingele R, Berger J, Alfke K, et al. Clinical and angiographic risk factors for stroke and death within 30 days after carotid endarterectomy and stent-protected angioplasty: a subanalysis of the SPACE study. Lancet Neurol 2008;7:216-222. [PubMed: 18242141]

26. Halliday A, Mansfield A, Marro J, et al. Prevention of disabling and fatal strokes by successful carotid endarterectomy in patients without recent neurological symptoms: randomised controlled trial. Lancet 2004;363:1491-1502. [PubMed: 15135594]

27. Roubin GS, Iyer S, Halkin A, Vitek J, Brennan C. Realizing the potential of carotid artery stenting: proposed paradigms for patient selection and procedural technique. Circulation 2006;113:20212030. [PubMed: 16636190]

28. Schouten O, Boersma E, Hoeks SE, et al. Fluvastatin and perioperative events in patients undergoing vascular surgery. N Engl J Med 2009;361:980-989. [PubMed: 19726772]

29. Landesberg G, Beattie WS, Mosseri M, Jaffe AS, Alpert JS. Perioperative myocardial infarction. Circulation 2009;119:2936-2944. [PubMed: 19506125]

30. Arias E, Curtin L, Wei R, Anderson R. United States decennial life tables for 1999-2001: United States life tables. Natl Vital Stat Rep 2008;57:1-36. 


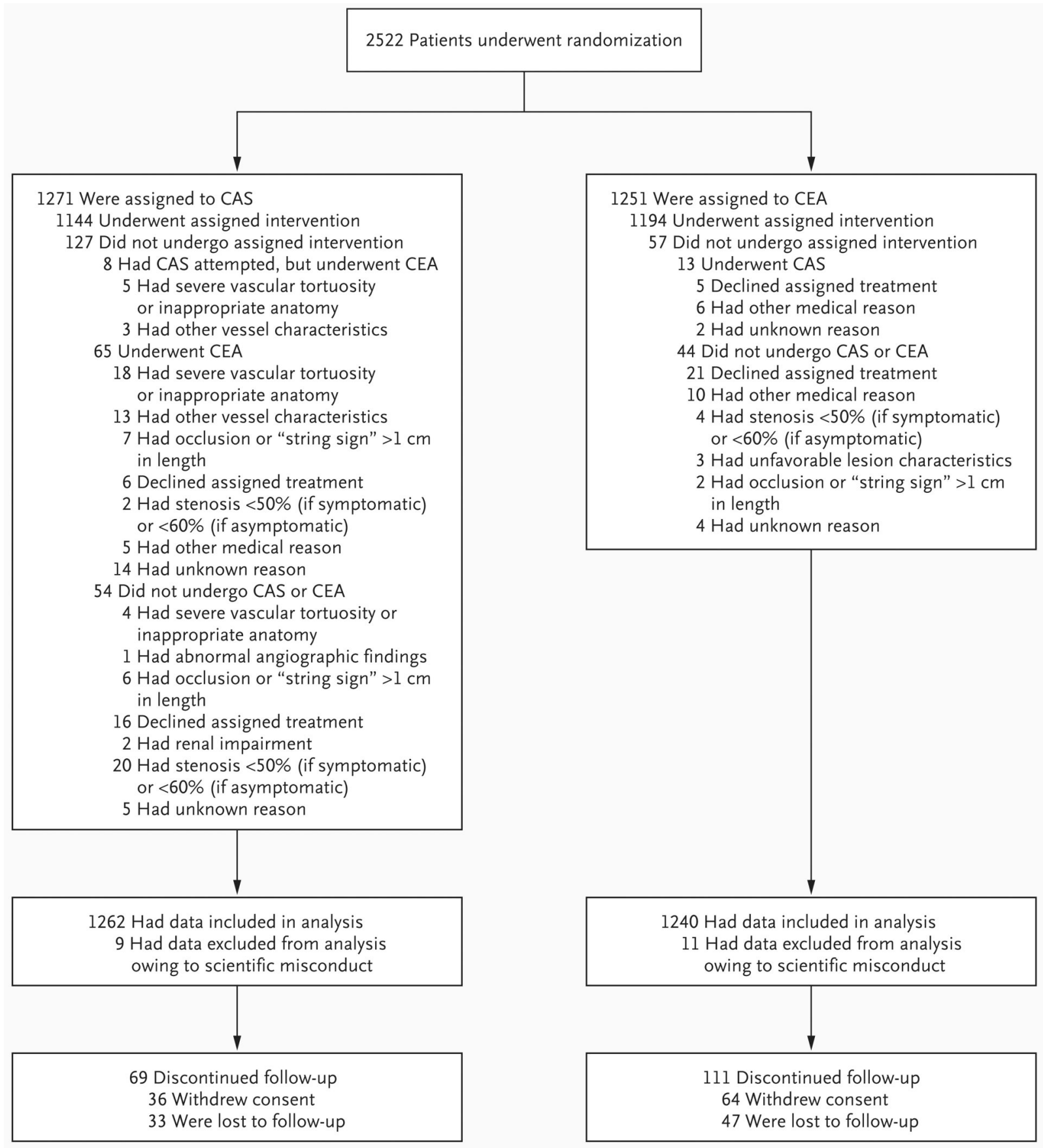

Figure 1. Randomization and Follow-up of the Study Patients

Patients were assessed for eligibility before randomization, but the number of patients assessed is not available, because screening logs were not maintained. CAS denotes carotid-artery stenting, and CEA carotid endarterectomy. 


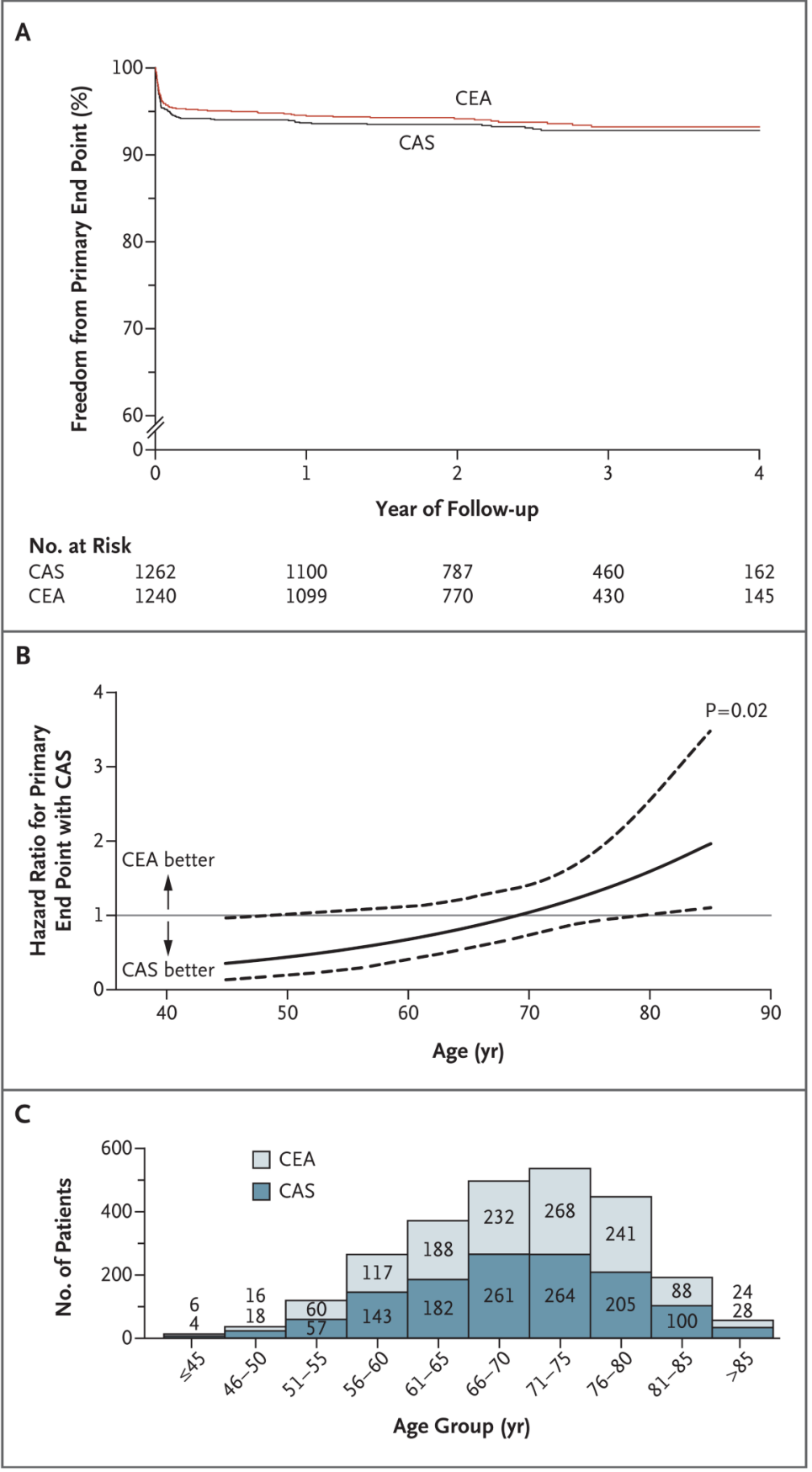

Figure 2. Primary End Point, According to Treatment Group

The primary end point was a composite of stroke, myocardial infarction, or death from any cause during the periprocedural period or ipsilateral stroke within 4 years after randomization. Panel A shows the Kaplan-Meier curves for patients undergoing carotid-artery stenting (CAS) and those undergoing carotid endarterectomy (CEA) in whom the primary end point did not occur, according to year of follow-up. Panel B shows the hazard ratios for the primary end point, as calculated for the CAS group versus the CEA group, according to age at the time of the procedure. The hazard ratios were estimated from the proportional-hazards model with adjustment for sex and symptomatic status. Dashed lines indicate the $95 \%$ confidence intervals. Panel $\mathrm{C}$ shows the numbers of patients in each age group. 
Table 1

Baseline Characteristics of the Study Population, According to Treatment Group.*

\begin{tabular}{|c|c|c|}
\hline Characteristic & $\begin{array}{l}\text { Carotid-Artery Stenting } \\
\quad(\mathrm{N}=1262)\end{array}$ & $\begin{array}{l}\text { Carotid Endarterectomy } \\
\qquad(\mathbf{N}=1240)\end{array}$ \\
\hline Age (yr) & $68.9 \pm 9.0$ & $69.2 \pm 8.7$ \\
\hline Male sex (\% of patients) & 63.9 & 66.4 \\
\hline White race $(\% \text { of patients })^{\dagger}$ & 92.9 & 93.5 \\
\hline Asymptomatic arteries (\% of patients) & 47.1 & 47.3 \\
\hline \multicolumn{3}{|l|}{ Risk factors ( $\%$ of patients) } \\
\hline Hypertension & 85.8 & 86.1 \\
\hline Diabetes & 30.6 & 30.4 \\
\hline Dyslipidemia ${ }^{t}$ & 82.9 & 85.8 \\
\hline Current smoker & 26.4 & 26.1 \\
\hline Previous cardiovascular disease & 42.4 & 45.0 \\
\hline Previous coronary-artery bypass & 19.9 & 21.5 \\
\hline \multicolumn{3}{|l|}{ Blood pressure (mm Hg) } \\
\hline Systolic & $141.6 \pm 20.2$ & $141.2 \pm 20.5$ \\
\hline Diastolic & $74.0 \pm 11.6$ & $73.9 \pm 11.5$ \\
\hline \multicolumn{3}{|l|}{ Percent stenosis at randomization } \\
\hline Moderate $(<70 \%)$ & 13.1 & 14.9 \\
\hline Severe $(\geq 70 \%)$ & 86.9 & 85.1 \\
\hline \multicolumn{3}{|l|}{ Stenosis characteristics (\% of patients) } \\
\hline Left carotid artery treated & 50.6 & 52.3 \\
\hline Contralateral occlusion & 2.7 & 3.2 \\
\hline \multicolumn{3}{|l|}{ Time from randomization to treatment (no. of days) } \\
\hline Median & 6 & 7 \\
\hline Interquartile range & 9 & 9 \\
\hline \multicolumn{3}{|l|}{ Procedural characteristics } \\
\hline Target-lesion length (mm) & $17.8 \pm 8.5$ & - \\
\hline Total length of stented segment (mm) & $34.4 \pm 7.3$ & - \\
\hline Balloon angioplasty before stenting (\% of patients) & 67.7 & - \\
\hline Embolic protection (\% of patients) & 96.1 & - \\
\hline \multicolumn{3}{|l|}{ Medical treatment (\% of patients) } \\
\hline Antiplatelet therapy $48 \mathrm{hr}$ before stenting & 97.7 & - \\
\hline \multicolumn{3}{|l|}{ During procedure } \\
\hline Heparin & 86.4 & - \\
\hline Bivalirudin & 13.6 & - \\
\hline Vasopressors & 29.9 & - \\
\hline \multicolumn{3}{|l|}{ After procedure } \\
\hline Any antiplatelet therapy & 99.0 & - \\
\hline Aspirin plus either clopidogrel or ticlopidine for $4 \mathrm{wk}$ & 87.9 & \\
\hline General anesthesia (\% of patients) & - & 90.0 \\
\hline Surgical technique (\% of patients) & & \\
\hline
\end{tabular}




\begin{tabular}{|lcc|}
\hline Characteristic & $\begin{array}{c}\text { Carotid-Artery Stenting } \\
(\mathbf{N}=\mathbf{1 2 6 2})\end{array}$ & $\begin{array}{c}\text { Carotid Endarterectomy } \\
(\mathbf{N}=\mathbf{1 2 4 0})\end{array}$ \\
Patch & - & 62.4 \\
Shunt & - & 56.7 \\
Medical treatment (\% of patients) & - & \\
Aspirin 48 hr before endarterectomy & - & 92.1 \\
Vasopressors during endarterectomy & - & 61.0 \\
Antiplatelet therapy after endarterectomy & & 91.1 \\
\hline
\end{tabular}

* Plus-minus values are means \pm SD. Dashes indicate not applicable.

${ }^{\dagger}$ Race was self-reported.

${ }^{*} \mathrm{P}=0.05$ for the difference in the baseline rate of dyslipidemia between the two groups. 


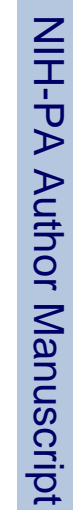

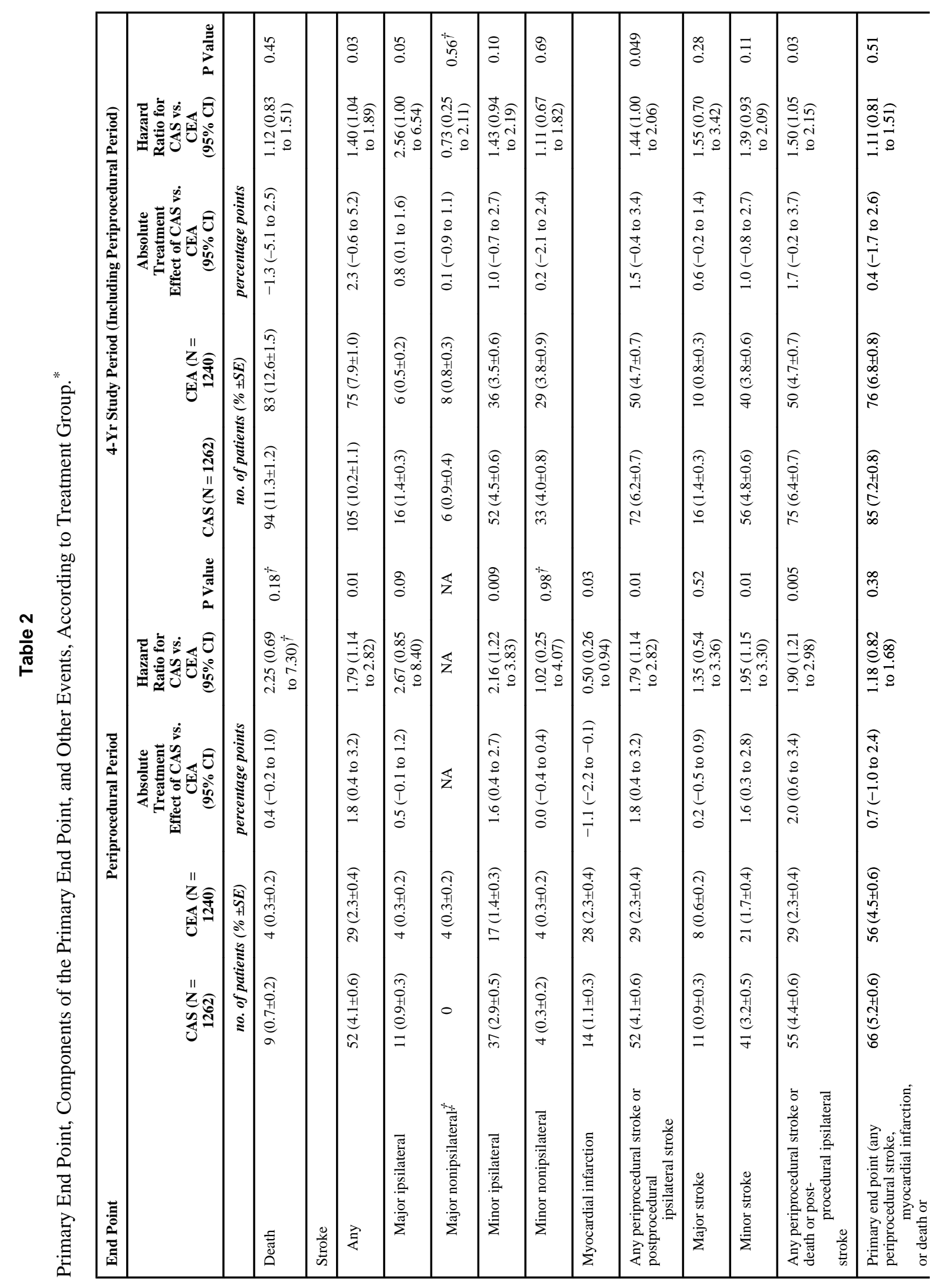

N Engl J Med. Author manuscript; available in PMC 2011 January 1. 


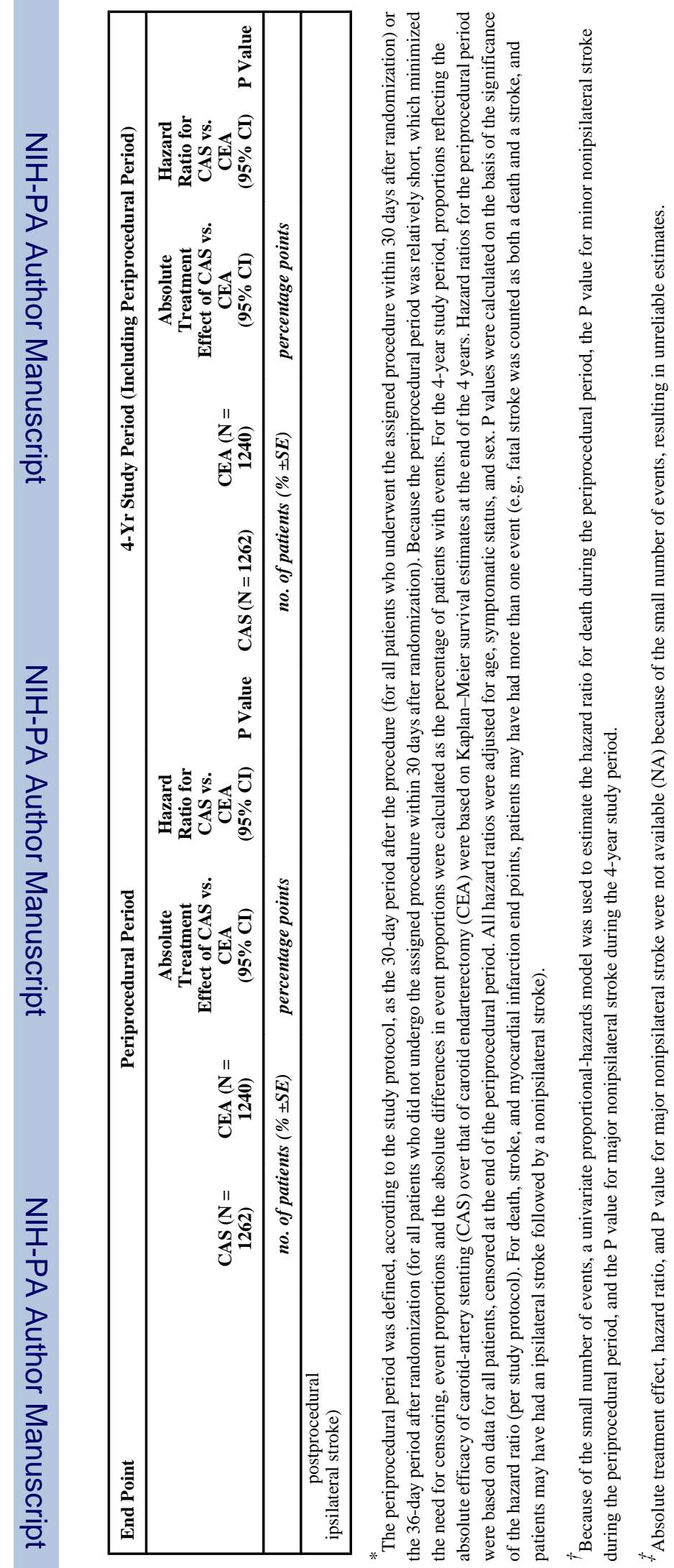

N Engl J Med. Author manuscript; available in PMC 2011 January 1. 


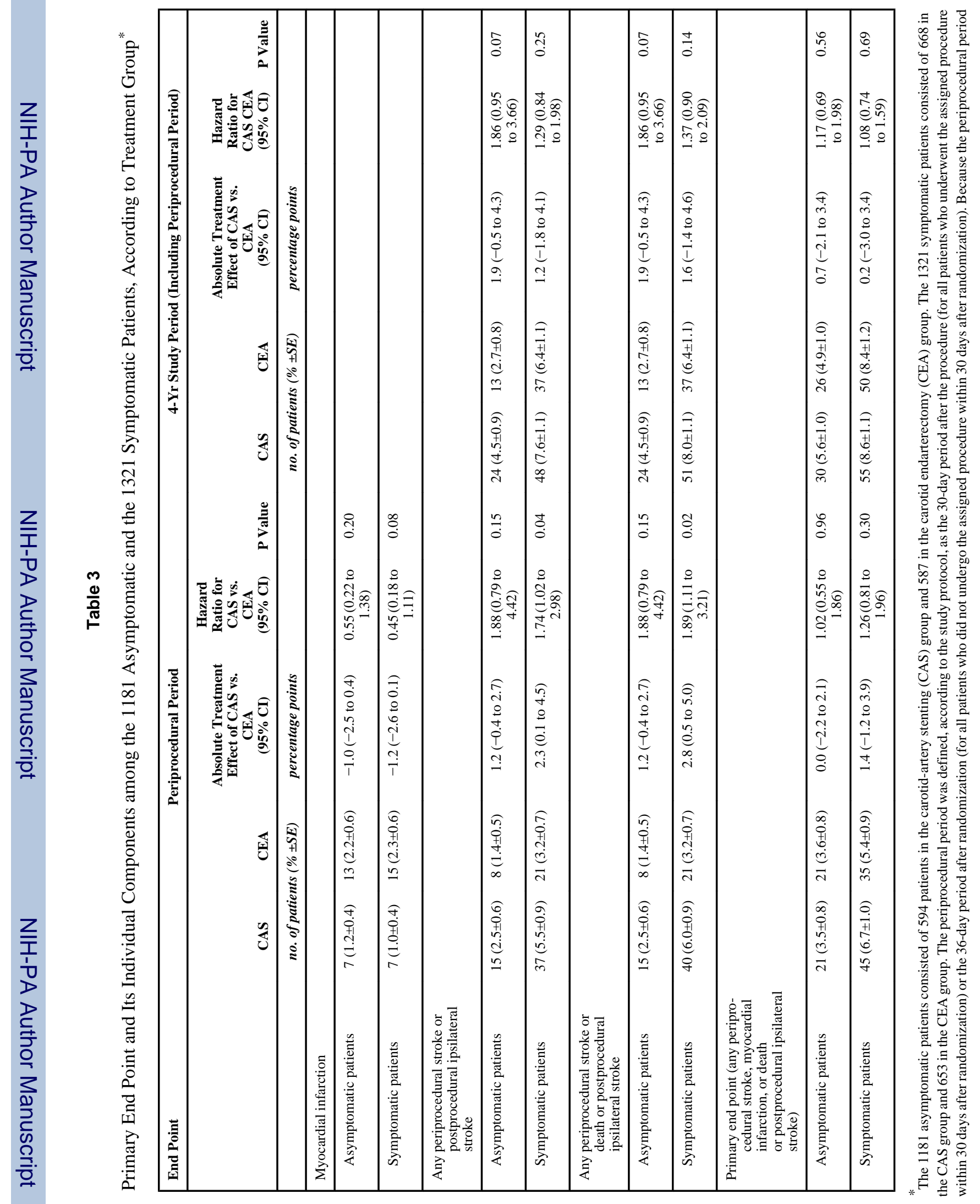

N Engl J Med. Author manuscript; available in PMC 2011 January 1. 


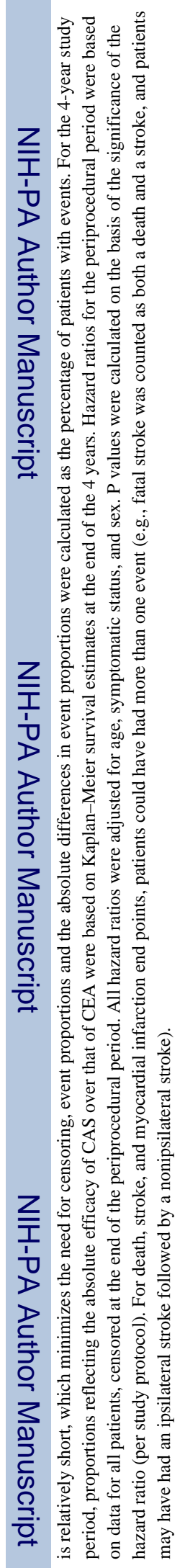

